means to increase it are sought and pursued. This requires taking authority away from government and non-government agencies outside the community and placing it, to the maximum feasible extent, in the hands of those allegedly being helped.

- Facilitate the meaningul participation of the entire displaced (or otherwise affected) community in mutual support and reconstruction efforts. Look out for people being excluded.

O Include appropriate mental health considerations in the relief effort from the immediate aftermath onwards. Hardly any of the relevant public health promotional measures require expertise in clientcentred psychological help.

O Review the applicability to populations collectively exposed to major disasters of models for understanding grieving that have been derived from those surviving in very different circumstances. Grief reactions seen in more ordinary circumstances are modified here by two peculiar influences. First is the desperate struggle, at the same time as loved ones are lost, to ensure survival of those still alive. The forced and unremitting exposure to many others similarly affected is the second.

Mental health professionals must contribute to decisions on what will be optimal with regard to each of these and to the delivery of what such an analysis yields. This will at times call for much patience and determination.

\section{References}

Alexander, D. A. (2005) Early mental health intervention after disasters. Advances in Psychiatric Treatment, II, 12-18.

Davidson, J. R. T. (2002) Surviving disaster: what comes after the trauma? British Journal of Psychiatry, I8I, 366-368.

de Vries, F. (1998) To make a drama out of trauma is fully justified. Lancet, 35 I, I579-1580.

International Federation of Red Cross and Red Crescent Societies (200 I) Psychological Support: Best Practices from Red Cross and Red Crescent Programmes. Geneva: International Federation of Red Cross and Red Crescent Societies.

Pupavac, V. (200I) Therapeutic governance: the politics of psychosocial intervention and trauma risk management. Disasters, 25 358-372.

Rose, S., Bisson, J. \& Wessely, S. (2002) Psychological debriefing for preventing post traumatic stress disorder (PTSD). Cochrane Database of Systematic Reviews, issue 2. Oxford: Update Software.

Roxane, C. H., Holman, E., Mclntosh, D., et al (2002) Nationwide longitudinal study of psychological responses to September II. JAMA, 288, I235-1244.

Simeon, D., Greenberg, B. A., Knutelska, M. P. H., et al (2003) Posttraumatic reactions associated with the World Trade Center disaster. American Journal of Psychiatry, 160, 1702-1705.

Sphere Project (2004) Sphere Handbook (revised edn). Geneva: Sphere Project. Available at http://www.sphereproject.org/ handbook/index.htm. Last accessed 20 April 2006.

van Ommeren, M., Saxena, S. \& Saraceno, B. (2005) Mental and social health during and after acute emergencies: emerging consensus? Bulletin of the World Health Organization, 83, 71-75.

\title{
Psychiatry in the Republic of Belarus
}

\section{Natallia Golubeva ${ }^{1}$, Kris Naudts², Ayana Gibbs ${ }^{3}$, Roman Evsegneev ${ }^{4}$ and Siarhei Holubeu ${ }^{5}$}

${ }^{1}$ Forensic Psychiatrist, Department of Forensic Psychiatry, State Medical Forensic Service, Minsk, Belarus, email doctor_golubeva@mail.ru

${ }^{2}$ Deputy Director, Forensic Psychiatry Teaching Unit, Department of Forensic Mental Health Science, Institute of Psychiatry, King's College London, UK

${ }^{3}$ Wellcome Clinical Research Fellow, Section of Cognitive Neuropsychiatry, Division of Psychological Medicine, Institute of Psychiatry, King's College London, UK

${ }^{4} \mathrm{Head}$, Department of Psychiatry, Belarusian Medical Academy for Postgraduate Training, Minsk, Belarus

${ }^{5}$ Forensic Psychiatrist, Department of Forensic Psychiatry, State Medical Forensic Service, Minsk, Belarus

he Republic of Belarus (ROB) covers 207600

$\mathrm{km}^{2}$ and has a population of about 10 million (Ministry of Statistics and Analysis, 2005). It was a member state of the former Soviet Union until it gained independence in 1991. Belarus is located between Poland, Lithuania and Latvia in the west, Russia in the east, and Ukraine in the south. Seventy-two per cent of the population live in an urban environment and $28 \%$ in rural areas. The average life span for men is 63 years and for women 75 years (Ministry of Public Health, 2005).

\section{Mental health policies and programmes}

Historically, psychiatry in the ROB has been strongly influenced by the classical Russian-German school of thought. This implied a biologically oriented approach and an emphasis on hospital in-patient treatment. Over the past 10 years there has been a dramatic shift in ideology, views, priorities, legislation and care models in psychiatry in several former Soviet republics. Many of these countries have welcomed modern
The country profiles section of International Psychiatry aims to inform readers of mental health experiences and

experiments

from around

the world. We welcome potential contributors.

Please contact Shekhar Saxena (email saxenas@ who.int). 
Anglo-Saxon approaches to mental health, but have implemented them to varying degrees. In the ROB, ICD-IO (World Health Organization, 1992) was officially introduced in 2002.

Mental healthcare is provided by the Health Service under the auspices of the Ministry of Public Health. The Health Service is funded by the state through general taxation. The country is in the World Bank's lower-middle-income group. The proportion of gross domestic product allocated to the health budget is $5.6 \%$. The per capita total expenditure on health is

In accordance with mental health legislation, people with schizophrenia, epilepsy, bipolar affective disorder and other psychiatric illnesses must receive their medication free of charge.

\section{The Ministry of Public Health has made it a requirement that every person diagnosed with a mental disorder is put on a register. Some employers may require a certificate from job applicants to demonstrate that they are not on this register before they consider hiring them.} $\$ 464$ (all prices here are reported in international dollars, i.e. after adjustment for purchasing power parity), and the per capita government expenditure on health is $\$ 402$ (World Health Organization, 2005).

There is no private psychiatric system and the state provides psychiatric care free of charge. Psychotropic drugs have increasingly been used since the early 1960s and are the main component of treatment today. In accordance with mental health legislation, people with schizophrenia, epilepsy, bipolar affective disorder and other psychiatric illnesses must receive their medication free of charge. For example, typical antipsychotics and some early atypicals, such as clozapine and sulpiride, are widely and freely available to patients. In recent years, one of the second-generation antipsychotics, risperidone, has also become available.

Mental health policy is set out annually by the Chief Psychiatrist at the Ministry of Public Health. For a few years now, a bio-psychosocial model and multidisciplinary teamwork have been advocated, as well as deinstitutionalisation and the development of community-based mental healthcare. However, in practice, the only component that has been realised so far is a substantial reduction in the number of psychiatric beds. The system of psychiatric care none the less remains highly centralised, with often large psychiatric hospitals and almost undeveloped social and community mental health services.

The first port of call for people with mental health problems is the so-called regional dispensary, where predominantly out-patient primary psychiatric care is provided by psychiatrists and psychiatric nurses. Patients receive counselling, are prescribed psychotropic medication or are referred for admission to the hospital. Some dispensaries have a few in-patient beds and some provide ambulatory psychotherapy. In addition, there are also specific dispensaries for children and adolescents, and for people with drug or alcohol addiction.

\section{In-patient care}

There are 14 general psychiatric hospitals, nine psychiatric departments at general medical hospitals, and six in-patient wards in dispensaries. There are 7225 beds available to psychiatric patients, of which 405 are for children. In addition, there are 1285 beds for addiction treatment. Over the past 5 years, the total number of beds has been reduced by about $30 \%$
(Ministry of Public Health, 2005). The State Mental Hospital in Minsk (the ROB's capital) is the largest general psychiatric hospital, with almost 2000 beds.

\section{Day care}

An intermediate type of psychiatric care is provided at day hospitals. Usually, this day care takes place on a special ward of a general psychiatric hospital or at a psychiatric dispensary. The patients come in the morning, receive their medications, participate in occupational therapy and return home in the evening.

\section{Out-patient care}

Out-patient psychiatric care is predominantly provided at psychiatric dispensaries by a psychiatrist and a nurse. They are located in cities and towns and cater for a geographically defined catchment area. In addition, some patients who attend the out-patient clinic are occasionally visited at home.

\section{Long-term care institutions}

Institutional care is under the auspices of the Ministry of Social Welfare. People with a chronic mental illness and people with learning disabilities are accommodated in special institutions. The standard of care and comfort is poor.

\section{Mental health legislation}

In 1999 the Mental Healthcare and Civil Rights Guarantee Law, inspired by its Russian equivalent, was adopted. This law stipulates that mental healthcare is guaranteed by the state and based upon the principles of law. It is voluntary and provided free of charge. Diagnoses are made in accordance with ICD-10. Treatment can be started only after written informed consent has been obtained from the patient.

Compulsory admissions of patients with mental disorders who pose a risk to themselves or others are overseen by local courts. These should be dealt with within 3 days of admission, but there is a significant delay in court procedures and patients are often well and fit to be discharged, or competent to consent to treatment, by the time the court attends to their case. Assessments are performed by at least three psychiatrists. Patients have the right to appeal at any time.

In addition, the Ministry of Public Health has made it a requirement that every person diagnosed with a mental disorder is put on a register. Some employers may require a certificate from job applicants to demonstrate that they are not on this register before they consider hiring them. Also, when a person on the register commits an offence a forensic psychiatric assessment is mandatory.

\section{Manpower and psychiatric associations}

In 2004, the incidence of mental disorders was 53931 and the overall number of people registered 
at psychiatric services reached 227 300. In the same year, there were 1073 psychiatrists (of whom 328 worked in addiction treatment settings), 162 psychotherapists, 10 clinical psychologists and 7 sexologists (Ministry of Public Health, 2005). There are no statistics concerning the number of psychiatric nurses.

In the State Mental Hospital in Minsk there are about 85 psychiatrists. Typically, two would be responsible for wards containing 50-60 patients. A typical psychiatrist in a dispensary would see more than 5000 patients per year (Ministry of Public Health, 2005).

The Belarusian Psychiatric Association (BPA) was created in 1996; it is a member of the World Psychiatric Association. The BPA initiated the drafting of the Mental Healthcare and Civil Rights Guarantee Law (see above) and implemented it in psychiatric practice. It drives all innovations in education and professional development and clinical practice. The vast majority of psychiatrists hold membership, for a small annual fee.

\section{Mental health training}

\section{Psychiatrists}

It takes 6 years to get a medical degree. There are 12 semesters of 5 months each and 6 weeks of clinical training in the summer. Only the very basics of psychiatry are taught during medical school. This leads to poor psychiatric knowledge among nonpsychiatrists, to whom people with mental health problems may present for the first time. To qualify as a psychiatrist takes only I year of training in a psychiatric hospital. This I-year training programme includes a full-time 3-month theoretical course in psychiatry, organised by the Belarusian Medical Academy for Postgraduate Training. At the end of this I-year programme, trainees have to pass a theory and practical examination before they can start practising independently. Every psychiatrist is required to attend a 2-week refresher course at least once a year.

\section{Child and adolescent psychiatrists}

A division for child and adolescent psychiatry and psychotherapy is being developed at the Belarusian Medical Academy for Postgraduate Training (the project began at the end of 2005). It is envisaged that training will be similar to that for general adult psychiatrists. Previously, people working in this field were general psychiatrists who had gained practical experience in child and adolescent psychiatry or psychotherapy.

\section{Psychiatric nurses}

Any generally trained nurse can work in a psychiatric hospital: there is no specific training for psychiatric nurses, nor are there any particular requirements to work in a mental health setting. However, when they have been working in a psychiatric setting for 3 years, they have to attend a 2-week course in psychiatry.

\section{Clinical psychologists}

Before 1994, psychology training did not involve clinical or psychotherapeutic components. Therefore, most psychologists in clinical posts perform only psycho-diagnostic testing. In 1994, the first faculty of clinical psychology was established, at Hrodno State Medical University. Since 200I, it has produced 30 clinical psychologists per year with advanced knowledge of clinical psychology and psychiatry.

\section{Research}

There has been some participation in a few international projects, such as the Collaborative Study on Alcohol and Injuries by the World Health Organization (200I), but in general research activity has been sparse.

\section{Human rights}

The Mental Healthcare and Civil Rights Guarantee Law states that mental healthcare should be provided by the state on observance of the principles of law, humanity and human rights. It explicitly stipulates that no one can have his or her civil rights restricted solely on the basis of having a mental illness, being on the register or living in a long-term care institution. It also states that methods of treatment should be used only with diagnostic and curative intentions and cannot be applied for punishment.

\section{Conclusions}

Psychiatry in the ROB has undergone major changes in the past decade. Modern mental health legislation has been implemented and deinstitutionalisation has been pursued. However, the latter has not been matched by the implementation of adequate community mental health services. Further development of professional training and research to underpin evidence-based practice are urgently needed.

\section{References}

Ministry of Public Health (2005) Public Health in the Republic of Belarus: An Official Statistics Collection. Minsk: Ministry of Public Health.

Ministry of Statistics and Analysis (2005) Republic of Belarus in Figures: Short Statistical Book. Minsk: Ministry of Statistics and Analysis.

World Health Organization (1992) International Classification of Mental and Behavioural Disorders (IOth edn) (ICD-I0). Geneva: $\mathrm{WHO}$.

World Health Organization (200I) Collaborative Study on Alcohol and Injuries Protocol. Geneva: WHO.

World Health Organization (2005) Mental Health Atlas. Geneva: $\mathrm{WHO}$.
Only the very basics of psychiatry are taught during medical school.

This leads to poor psychiatric knowledge among non-psychiatrists, to whom people with mental health problems may present for the first time. 